\title{
RTG IMPACT RESPONSE TO HARD LANDING DURING MARS ENVIRONMENTAL SURVEY (MESUR) MISSION
}

\author{
A. Schock and M. Mukunda \\ Fairchild Space
}

\section{ABSTRACT}

The National Aeronautics and Space Administration (NASA) is studying a seven-year robotic mission (MESUR, Mars Environmental Survey) for the seismic, meteorological, and geochemical exploration of the Martian surface by means of a nerwork of -16 small, inexpensive landers spread from pole to pole. To permit operation at high Martian latitudes, NASA has tentatively decided to power the landers with small RTGs (Radioisotope Thermoelectric Generators). To support the NASA misston study, the Department of Energy's Office of Special Applications commissioned Fairchild to perform specialized RTG design studies. Those studies indicated that the cost and complexity of the mission could be significantly reduced if the RTGs had sufficient impact resistance to survive ground impact of the landers without retrorockets. Fairchild designs of RTGs configured for high impact resistance were reported previously. Since then, the size. configuration, and impact velocity of the landers and the power level and integration mode of the RTGs have changed substantially, and the previous impact analysis has been updated accordingly. The analytical results, reported here, indicate that a lander by itself experiences much higher $g$. loads than the lander with an integral penetrator; but that minor modifications of the shape of the lander can very substantially reduce the maximum 8 -load during landing, thus eliminating the need for retrorockets for RTG survival.

\section{INTRODUCTION}

NASA has been studying misslons to distribute a large number $(-16)$ of small unmanned landers over the surface of the Martlan globe, ranging from equatorial to polar reglons. These studies have gone under the name of Mars Global Network at NASA's Jet Propulsion Laboratory (JPL) [1] and of Mars Experimental Survey (MESUR) at NASA's Ame's Research Center [2]. The most important characteristic of a Mars network mission Is that it will send landers to widely dispersed sites on the Martian surface.

When fully deployed, the robotic landers will form a global network to simultaneously collect seismic and meteorologlcal data over a perlod of seven years. The scientific objectlves of the mission will Include data sampling relating to the internal structure of the Martian crust, global clrculation, geochemistry of the soil, the chemical composition of residual polar caps, and highresolution surface imaging. Particular emphasis will be placed on hard-to-reach sites (polar deposits, rugged volcano flanks, eto.) that would be difficult or impossible to Investigate by any other means.
Since the simultaneous operation of large number of landers over a long period of time is required, the landers must be capable of long life. They must be simple so that a large number can be sent at affordable cost, and yet rugged and robust in order to survive a wide range of landing and environmental conditions.

NASA has baselined the use of Radioisotope Thermoelectric Generators (RTGs) to power the probe, lander, and scientific instruments. Considerations favoring the use of ATGs are their applicablity at both low and high Martian latitudes, their ability to operate during and after Martian sandstorms, and their ability to withstand Martian ground impacts at high velocities and $\mathrm{g}$-loads.

High Impact resistance of the RTGs can be of critical importance In reducing the complexity and cost of the lander. This is because experlence has shown that the other components of the lander can be adequately hardened, so that the RTG's impact tolerance is the controling determinant of allowable impact velocity. Hard impacts could of course be avoided by using retrorockets to decelerate the lander before Impact, as was done for the 1976 Viking landings on Mars. But deceleration systems to achleve soft landing require complex attitude control systems and tend to be quite massive and costly. This was acceptable for the large Viking landers, but would not be for the 16 small landers for the present mission, which must be designed for minimum complexity and cost.

Thus, the greater the impact velocity that the RTG can survive, the lower the complexity, mass, and cost of the system required to decelerate the spacecraft. Therefore, high impact resistance was one of the dominant goals for the RTG designs we presented in an earlier paper [3]. Quasi-static analyses described in that paper indlcate that those RTGs could withstand impact loads up to $2000 \mathrm{~g}$, and impact analysis showed that the lander design initlally favored by JPL resulted in a peak g-load of $1300 \mathrm{~g}$ at the maximum predlcted impact velocity of 100 $\mathrm{m} / \mathrm{s}$. But that design called for a mechanically coupled penetrator and lander. The presence of the penetrator was beneficial, in that it slowed down the decoleration process and thus reduced the maximum g-load experienced by the lander.

Subsequently, NASA's Ames Research Center proposed a smaller and less costly design concept for the MESUR mission, and was authorized by NASA to conduct a more detailed study based on that concept. The results of that study were reported last year [2], and the study is now continuing at JPL. 
The smaller and lighter lander design proposed by NASAAmes has a significantly lower impact velocity (30 Instead of $100 \mathrm{~m} / \mathrm{s}$ ) but does not have a penetrator to help slow down the lander. The goal of the present paper is to determine the maximum g-load that would be experlenced by the lander without penetrator (and without retrorockets or air bags), and to determine how much those g-loads could be reduced by minor changes In the lander design, and to analyze the resultant stresses and survivability of the impact-resistant ATG on such a lander.

\section{RTG DESIGN}

The ultimate power requirement for the mission is still uncertain, but the basic RTG design approach would remain the same. The study reported last year [3] presented two illustrative RTG designs: a 9-watt design for direct communication to Earth and a 3-watt design for communlcation through an orbiting relay. Both designs strove to maximize the use of previously developed technology, Including the General Purpose Heat Source (GPHS) [4] used in the Galleo and Ulysses ATGs [5]; the SiGe thermoelectric materials employed in the RTGs for the Voyager, LES 8/9, Galleo and Ulysses missions, and the multicouples developed for DOE's Mod-ATG program $[6,7]$. Modifications were Introduced only where necessary to improve the RTG's Impact reslstance and to meet other mission requirements.

Fairchild has completed detailed thermal, electrical, and mass analyses of the two RTG designs and a prellminary quasi-static analysis of the their Impact resistance. A brlet discussion of the 9-watt design follows, the detalls of which have been presented in the earlier paper [3].

To take advantage of prevlously developed technology and safety tests, the heat source should be a derlvative of the flight-qualifled 250-watt Genera! Purpose Heat Source (GPHS) module, depicted in Figure 1.

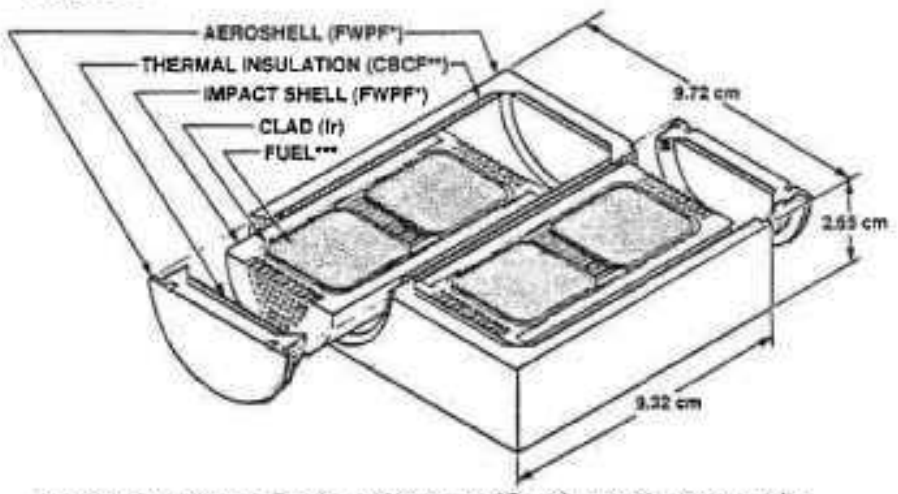

-Fine-Weave Pierced Fabric, a 90\%-dense 30 earbon-carbon composite -Carbon-Bonded Carbon Fibers, a 10\%-dense high-temperature insulator $* 62.5$-watt ${ }^{236}$ puO $_{2}$ pellet

Figure 1. General-Purpose Heat Source Module (250 Watts)
As shown, each GPHS module contains four fuel capsules. Therefore, if we wish to use the standard GPHS fuel capsules the heat source's thermal power can only be varied in steps of 62.5 watts.

For a 9-watt RTG, the thermal power requirement can be satistied with just three of the four standard fuel capsules shown in Figure 1. The left segment of Figure 2 shows a heat source containing three such capsules, embedded in an impact shell, thermal insulation, and aeroshell of the same graphitic matorials and shell thicknesses as the standard GPHS module.
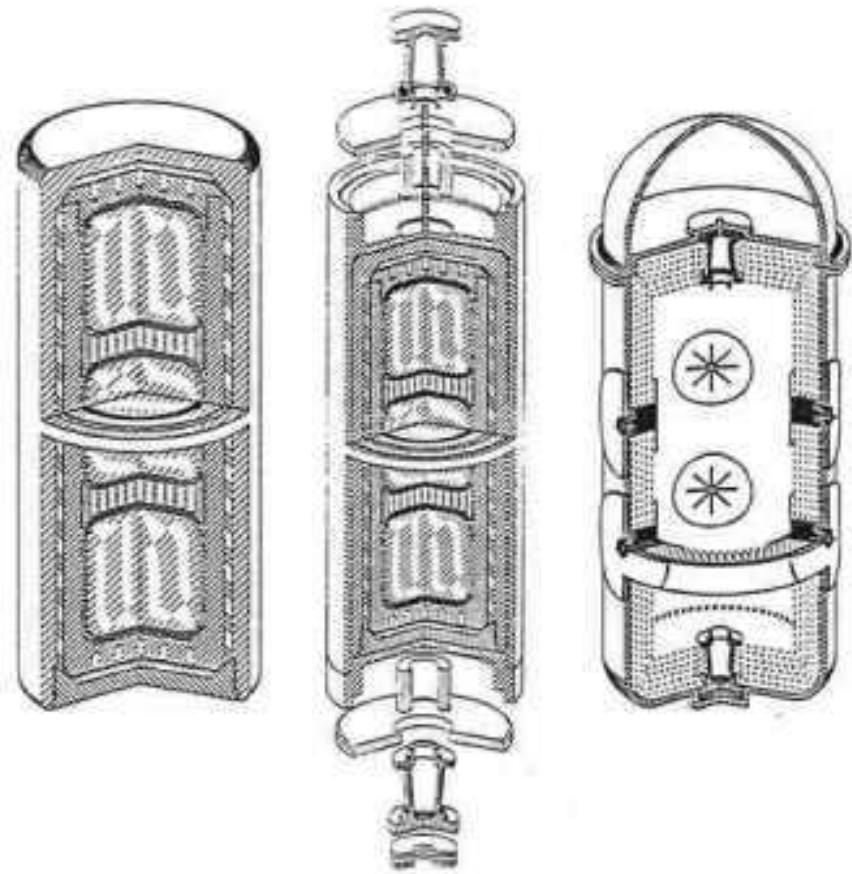

Figure 2. Principal Subsystems of 9-Watt RTG

Similarly, the figure's middle segment shows the heat source with its canister and support structure. The purpose of the canister is to separate the helium generated by alpha decay from the thermoelectric converter surrounding the heat source.

The right segment of Figure 2 shows a sectloned view of the 9-watt converter, without the heat source. As seen, it contains six thermoelectric multicouples similar to those used in the Modular RTG $[6,7]$. They are arranged in two layers of three multicouples. The figure segment shows that the multicouples' heat collectors cover only a small fraction of the heat source surface. And yet the multifoil insulation is so effective that about two thirds of the generated heat flows through the thermoelectric elements.

Figure 3 depicts the assembled 9 -watt RTG, with its dimensions and mass breakdown; and Figure 4 shows its salient operating temperatures and performance characteristics. 


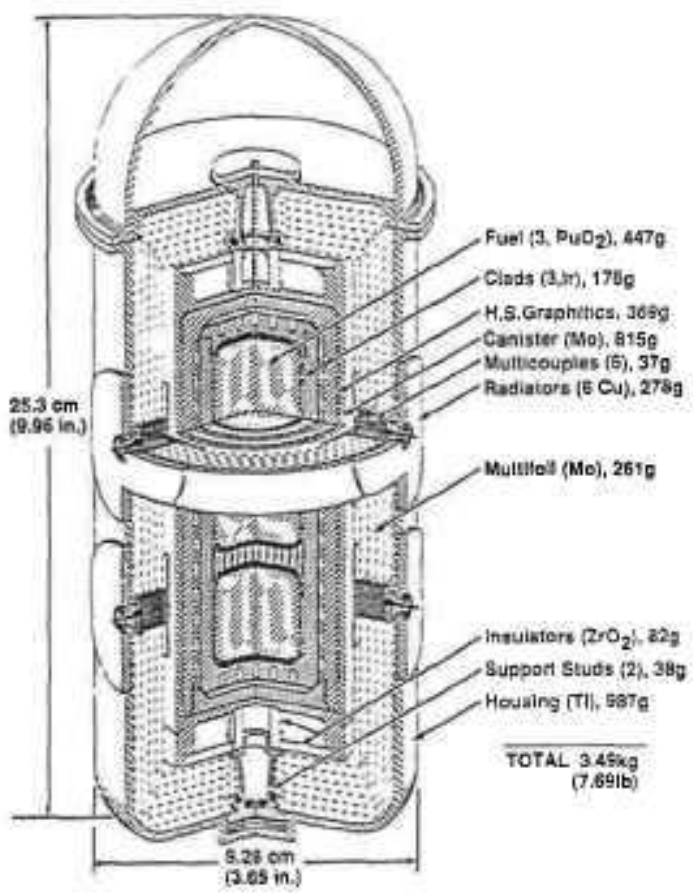

Figure 3. Nine-Watt RTG

\section{INITIAL LANDER DESIGN}

An earlier design concept by JPL [1] assumed a combination penetrator/lander, with the sharp-nosed penetrator acting as a forebody and the blunt-nosed lander acting as the aft-body. As illustrated in Figure 5, the two are together at impact but are free to separate after impact.

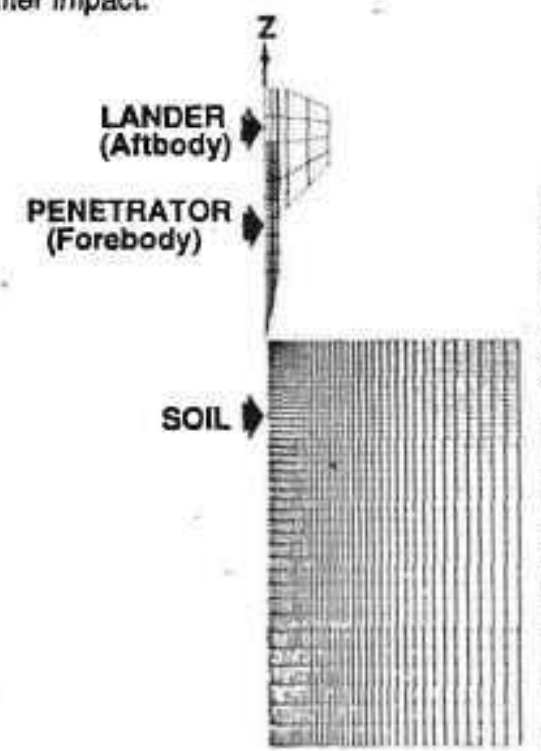

TIME, msec PENETRATION, $\mathrm{m}$ VELOCTY, $\mathrm{m} / \mathrm{sec}$ G-LOAD

0
$0 / 0$
$00 / 100$
$0 / 0$

4

$0.39 / 0$

$92 / 92$

$432 / 432$

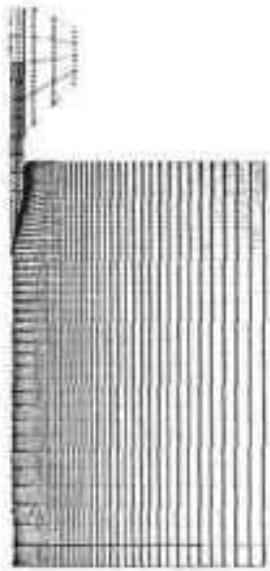

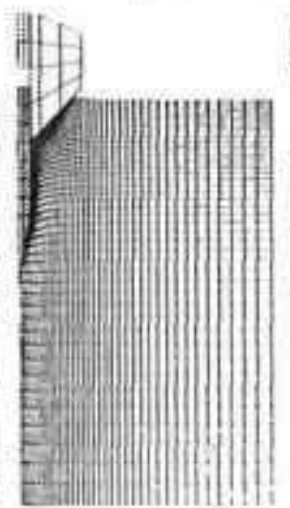

8

$0.73 / 0.15$

$76 / 24$

$540 / 1340$

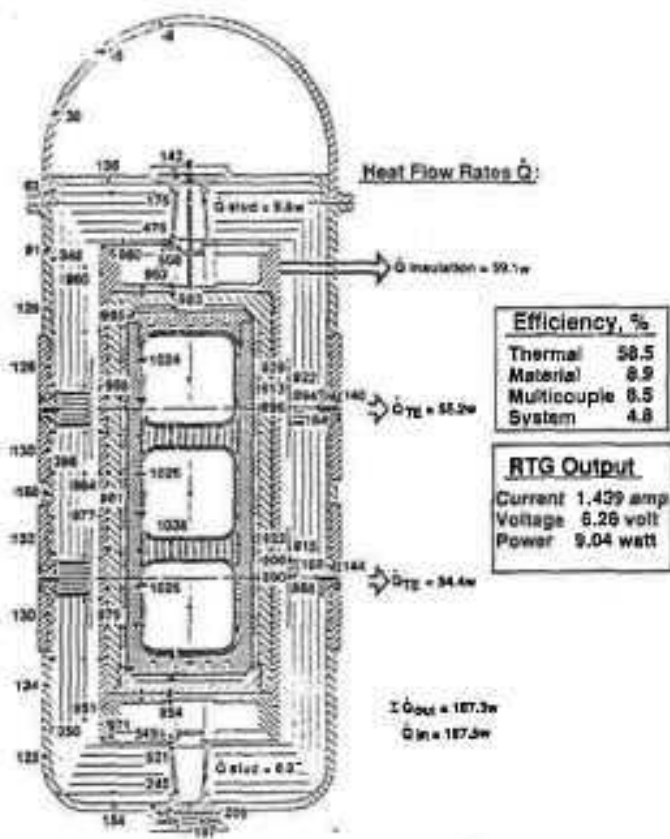

Figure 4. Operating Temperatures $\left({ }^{\circ} \mathrm{C}\right)$ and Heat Flow Rates in 9-Watt RTG

Detalled hydrocode calculations [3] were performed by Fairchild personnel to assess the peak gloads experienced by the penetrator/lander combination after impacting the Martian surface at $100 \mathrm{~m} / \mathrm{sec}$, the velocity predicted by JPL if no retrorockets are used. As Illustrated in Flgure 5, these calculations showed peak deceleration loads of $540 \mathrm{~g}$ and $1340 \mathrm{~g}$ and maximum penetration depths of about $2 \mathrm{~m}$ and $0.2 \mathrm{~m}$ for the penetrator and the lander, respectively. A quasi-static impact stress analysis presented in the same paper predicted that the RTGs depicted in Figure 3 have sufficient impact resistance to withstand the predicted $1340-\mathrm{g}$ load, thus enabling the survival of the penetrator/landers without the use of retrorockets.
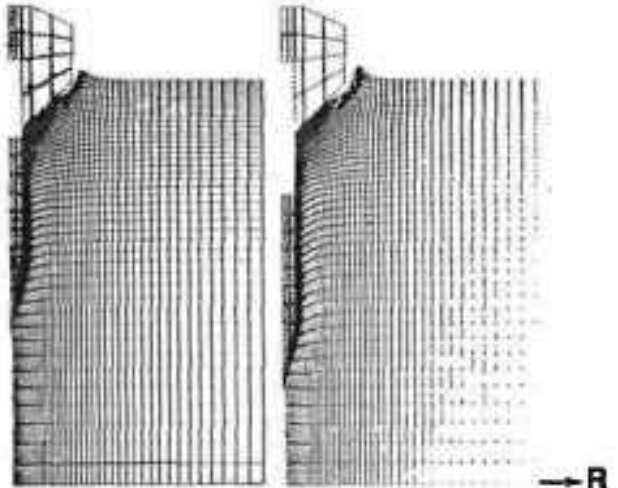

12
$1.01 / 0.20$
$62 / 2$
$310 / 400$

16

$1.23 / 0.20$

$52 / 1$

$270 / 0$

Figure 5. Deceleration of Penetrator/Lander After Impact (Results of Hydrocode Analysis) 
The less costly MESUR mission [2] subsuquently proposed by NASAIAmes called for a total of sixteen landers, to be launched In groups of four at two-year Intervals. After launch, each group was to separate Into four probes. These would then fly independently to their Martian destinations, ranging from equatorial to polar reglons. The proposed probes were substantially smaller and lighter than those of the previous JPL design.
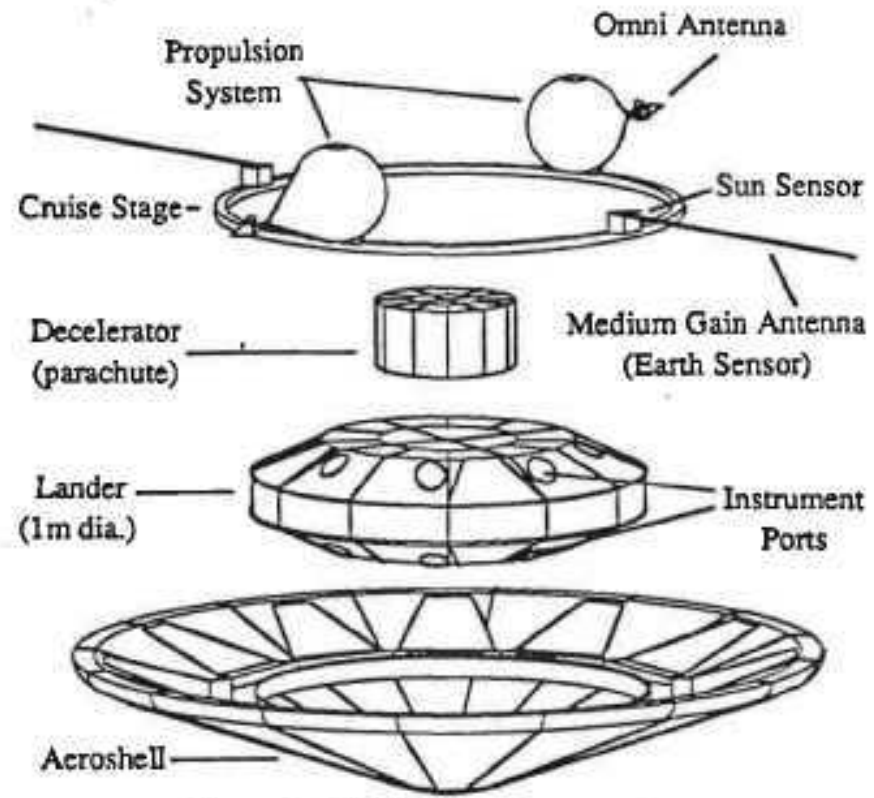

Figure 6. MESUR Probe Components

As shown in Figure 6, the design consists of four principal parts: a cruise vehicle, an aeroshell (for atmospherlc entry), a parachute assembly (for preimpact deceleration), and the lander. The cruise stage, aeroshell and the decelerator are necessary for Interplanetary flight, atmospherlc entry, descent and landing.

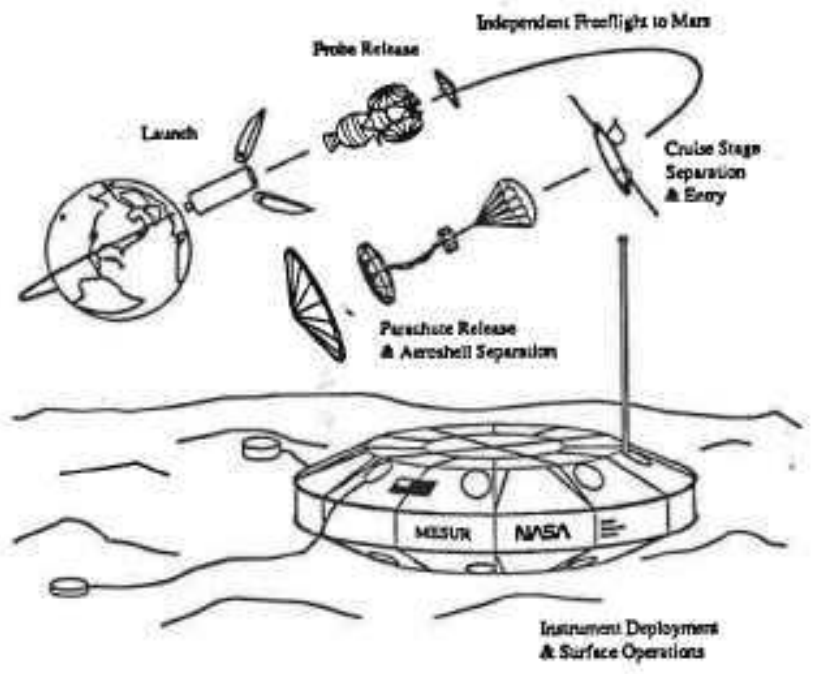

Figure 7. MESUR Mission Summary
The Ames baseline mission scenario, lllustrated in Figure 7, assumes that each of the probes files Independently to Mars. Each of these systems Is separated from the probe as Its portion of flight is completed. The cruise stage is separated before atmospheric entry, after which the aeroshell separates and falls to the Martian surface. The parachute is then deployed to slow down the lander, and soparates from the lander and is carried away by a small rocket just before impact.

As deplcted In Flgure 8, the lander designed by Ames is disk-shaped, about $1 \mathrm{~m}$ in diameter and $0.25 \mathrm{~m}$ thick, with a total mass of $78.6 \mathrm{~kg}$. The RTG is located Inside the lander. The Ames study predicted that the parachute would slow the lander to a maximum vertical velocity of $30 \mathrm{~m} / \mathrm{s}$, the horizontal velocity being equal to the local wind velocity (up to $10 \mathrm{~m} / \mathrm{s}$ ). Without retrorockets or alr bags, that would be the velocity at which the lander impacts the Martian soil.

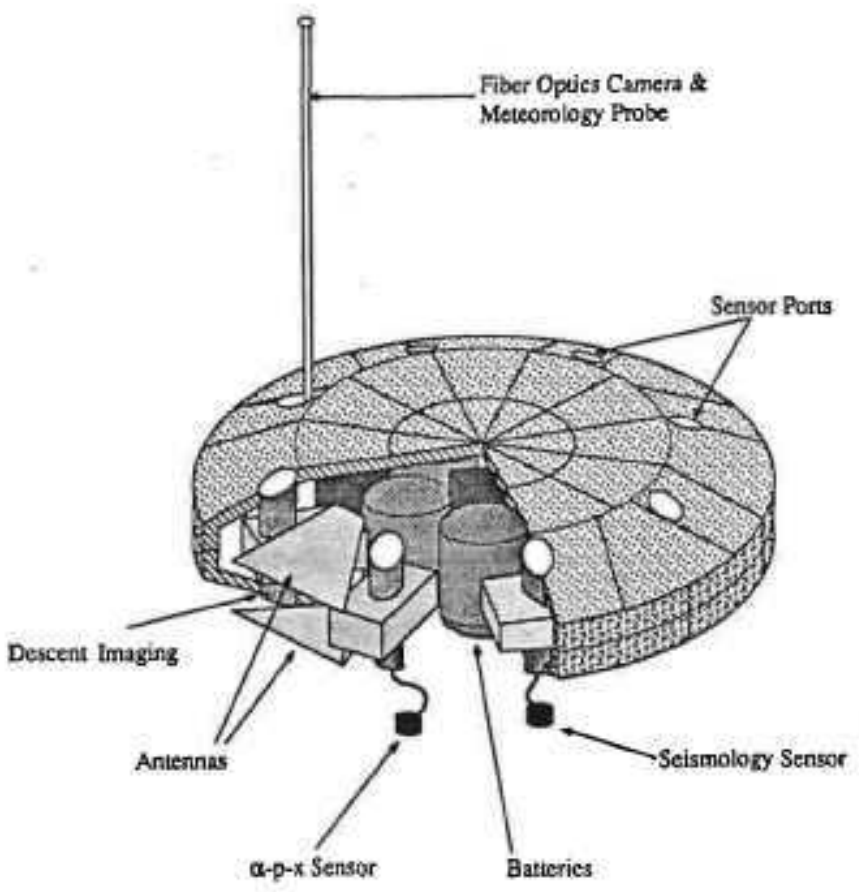

Figure 8. MESUR Lander

To determine the $\mathrm{g}$-loads produced by such an Impact, a detalled two-dimensional axisymmetric model of the Impact of the lander on representative Martian soll was set up, Initlally without cross-wind. The analysis employed the continuum-mechanics finite-difference code PISCES [8]. The lander was conservatively modeled as a rigld body impacting Martian soil at 30 $\mathrm{m} / \mathrm{s}$. The soll was modeled using a shock equation of state, based on an experimentally determined relationship between shock and particle velocities [9]. The model was based on a bulk sound speed of 172 $\mathrm{m} / \mathrm{s}$, a Gruneisen coefficient of 0.25 and a Mohr Coulomb yield model with a yleld stress of 350 bars. 

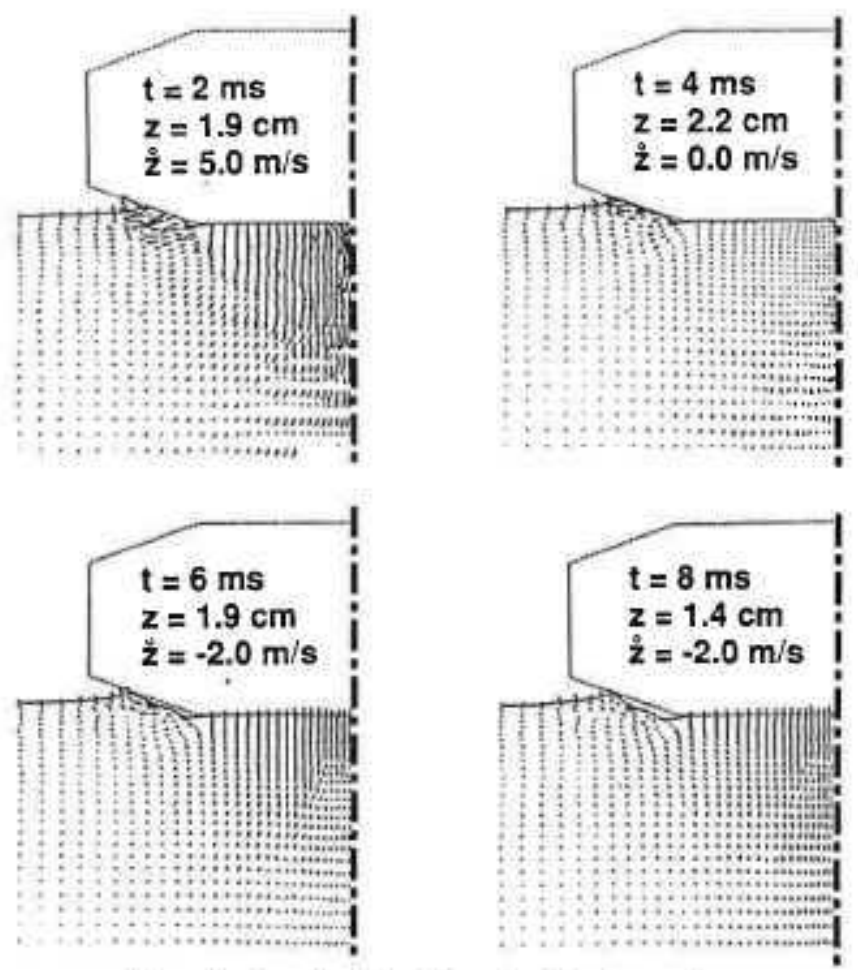

Figure 9. Deceleration of Lander After Impact

The displacement of the soil as the lander penetrates it is shown In Figure 9 at intervals of $2 \mathrm{~ms}$, and the lander's velocity proflle is shown in Figure 10. As seen, it penetrates to a depth of $2.3 \mathrm{~cm}$ in $4 \mathrm{~ms}$, after which it rebounds. As shown in Figure 10, the lander experiences extremely rapid initial deceleration. resulting in unacceptably high g-loads of $-1.5 \times 10^{5}$ in the first $100 \mu \mathrm{s}$ after Impact. Thus, the Ames lander design would experience substantially higher g-loads than the $1340 \mathrm{~g}$ peak load calculated for the combination penetrator/lander previously proposed by JPL.

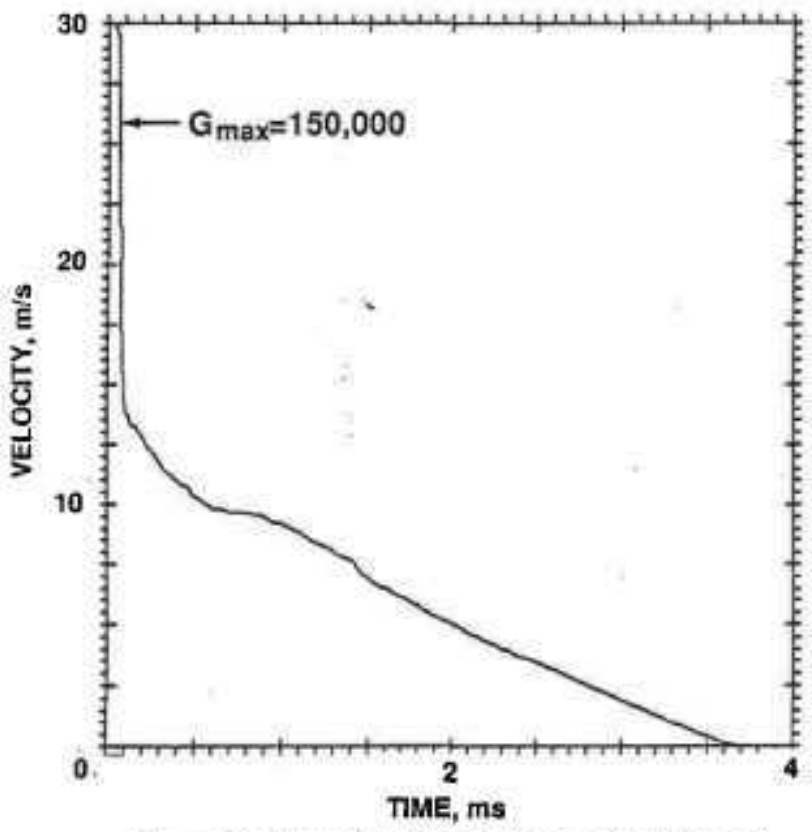

Figure 10. Velocity Proffle of Lander After Impact

\section{SHAPE MODIFICATION}

The excessive $g$-load experienced by the lander alone was thought to be the result of the shape of the Ames lander. A large area of the impacting face contacted the Martian soil, causing the lander to decelerate almost instantaneously and resulting in very high g-loads. To attempt to reduce those g-loads, a number of modified but still similar axisymmetric lander shapes were analyzed for the same 1-meter lander diameter and $79 \cdot \mathrm{kg}$ mass and the same $30 \mathrm{~m} / \mathrm{s}$ impact velocity. Several of the modified designs were found to be surprisingly effective in reducing the maximum $\mathrm{g}$-load to survivable levels. The design yielding the most favorable results is deplcted in Figure 11.
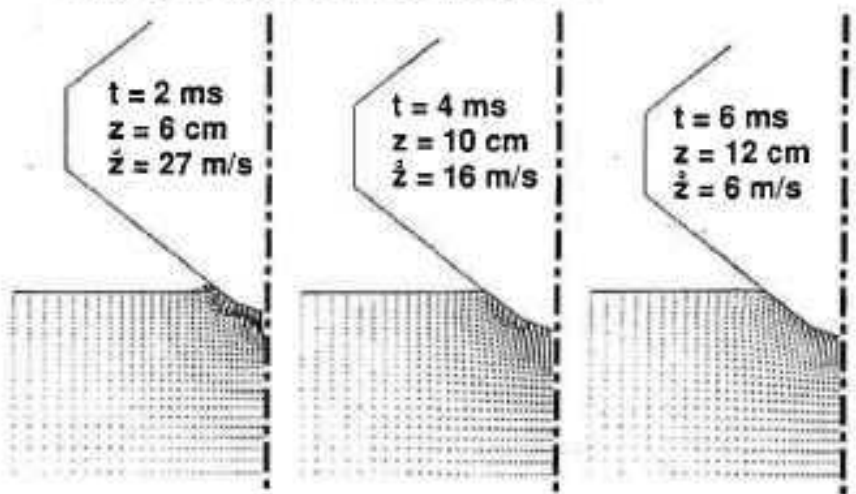

Figure 11. Deceleration of Modified Lander After Impact

Instead of the Martian soil being impacted by a blunt-nosed lander, the large Impacting face was split Into two coaxial conical faces. The inner one $(0<\mathrm{r}<$ $7.8 \mathrm{~cm}$ ) has a cone angle of $100^{\circ}$, and the outer one $(7.8<r<50 \mathrm{~cm})$ has a cone angle of $140^{\circ}$. For that shape, the displacement of soil and the penetratlon of the lander is shown In Flgure 11 at Intervals of $2 \mathrm{~ms}$, and the velocity profile of the lander as it penetrates the Martlan soil is displayed in Figure 12. As shown, the modifled lander penetrates the soll to a depth of $12 \mathrm{~cm}$ in $7.5 \mathrm{~ms}$, and experiences a peak g-load of only $500 \mathrm{~g}$, which is far below the $150,000 \mathrm{~g}$ of the Ames design shown in Figure 9, and is even below the peak load for JPL's earller penetrator/lander combination.

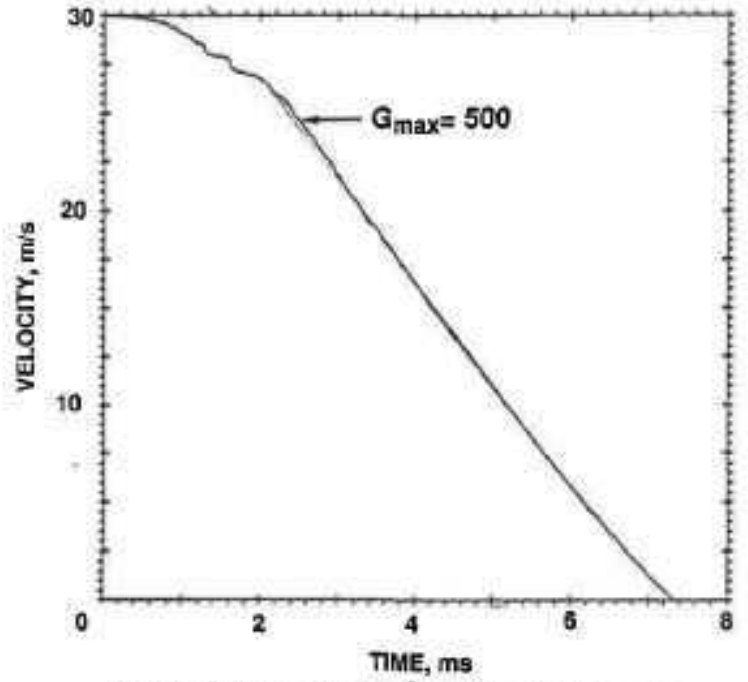

Figure 12. Velocity Profile of Modified Lander 


\section{D CALCULATIONS}

The above described analysis assumed vertical descent (i.e., no cross-wind) and a level Martian surface. Nelther assumption may be true for a particular landing. To determine the effects of a cross-wind or of a sloping ground, additional analyses were carried out. Since these problems are no longer axisymmetric, a 3-dimensional Lagranglan code had to be employed instead of the 2dimensional PISCES code used earlier.

The 3-dimensional calculations were performed by means of the AUTODYN-3D code [10] which is a fully integrated three-dimensional engineering analysis program specifically designed for non-linear dynamic problems. The AUTODYN programs are engineering and scientific tools being used for the solution of a wide variety of applications, Including the dynamics of impact and penetration. For each problem, a three-dimensional mesh with 30,000 grid points was generated using the Lagrange processor resident in AUTODYN-3D to depict the lander and the soil. The Lagrange mesh moves and distorts with the physical material, which gives an efficient calculation of large deformations and a good definition of free surfaces and material interfaces.

Three specific cases were analyzed using AUTODYN3D, with the results depicted in Flgure 13.
Case 1:

Level Ground No Cross-Wind
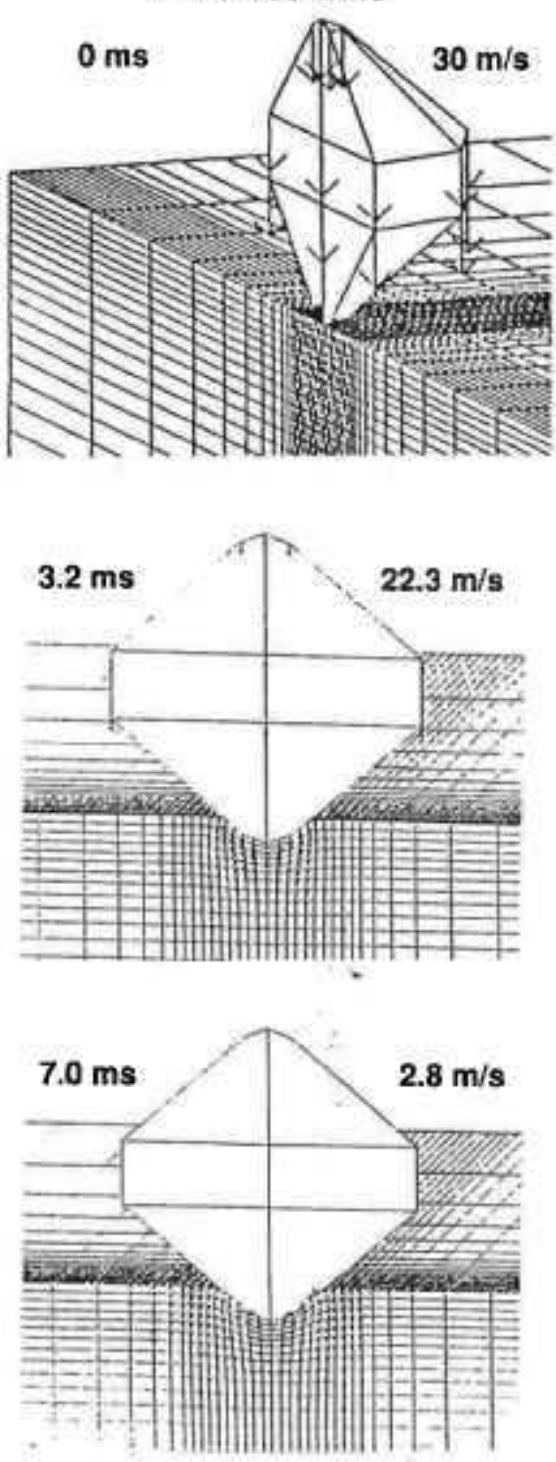

Case 2: Sloping Ground No Cross-Wind
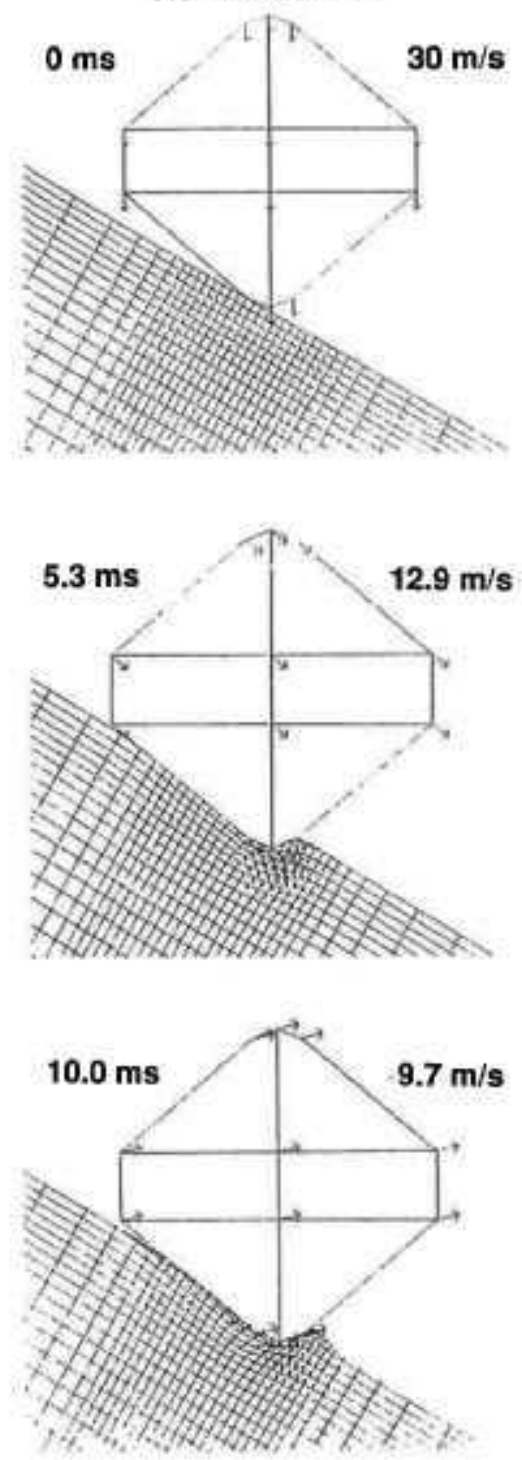

Case 3:

Level Ground $10 \mathrm{~m} / \mathrm{s}$ Cross-Wind

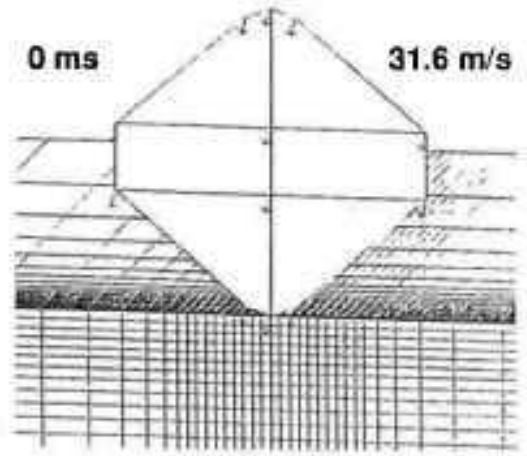

Figure 13. Effect of Sloping Ground and Cross-Wind on Lander Deceleration 
Case 1-A reference case, with the modified lander impacting level Martian soil at $30 \mathrm{~m} / \mathrm{s}$ without cross-wind. This calculation provides a check against the results described in the previous section using the PISCES-2D code,

Case 2 - The lander Impacting the soll which is sloping at $30^{\circ}$ to the horizontal, and

Case 3 - The lander having a vertical velocity of $30 \mathrm{~m} / \mathrm{s}$ and a horizontal component of $10 \mathrm{~m} / \mathrm{s}$ to account for the cross-wind at the Martlan surface.

For each case, Figure 13 shows Illustrative snapshots at three different times. Each of the nine pictures shows the tIme after impact, the residual total (not vertical) velocity of the lander, the lander's penetration into the Martian soll, and the instantaneous velocity vectors of the lander and soil grid points. Note that in the last picture for each case the vectors Indicate that the lander's vertical velocity has passed through zero and the lander is rebounding. Also note that in the case of the sloping ground the lander has moved quite a bit to the right (downhili), and in the case of the cross-wind the lander has moved to the left (downwind). The pictures illustrate the power and versatility of the AUTODYN-3D computer code for analyzing complex collisions and deformations on a microsecond time scale.

The deceleration of the lander for the three cases is shown in Flgure 14. As can be seen, although the three cases represent very different situations, they yleld surprisingly similar velocity profiles and maximum g-loads $(-500 \mathrm{~g})$. Thus the modified lander design would be beneficial not only for normal impacts but also in the case of cross-winds and sloping ground. Thus, a rolatively minor modification of the lander's shape can substantially reduce the impact loads it experiences.

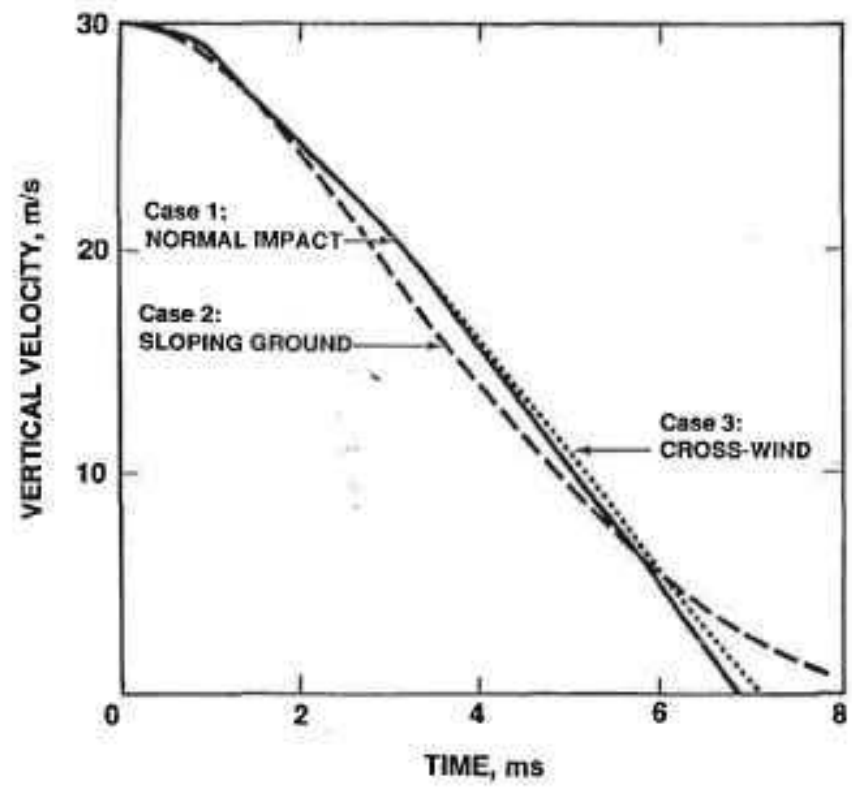

Figure 14. Effect of Impact Orientation on Lander Deceleration
Note that Case 1 is axisymmetric and essentially Identical to the problem previously solved by the 2DPISCES code. Comparison of Figures 12 and 14 show that the AUTODYN-3D code and the 2D-PISCES code yield very similar results for axisymmetrlo problems. This lends confidence in the validity of using the AUTODYN code for asymmetric as well as axisymmetric problems.

\section{IMPACT RESPONSE OF RTG}

As explained in the prevlous paper [3], the impact tolerance of the RTG is dominated by the response of the cantilevered thermoelectric multicouples to exial and lateral g-loads, specifically by the tenslle and bending strosses at the hot and cold ends of their thermoolectric leg assemblles. To determine those stresses, a quasistatic analysis was carried out. Since the orientation of the lander at Impact is not predictable, both axial and lateral $g$-loads had to be analyzed.

The analyses showed that for an axial g-load G, the tenslle stress at the leg assembly's cold face is given by $\sigma_{\mathrm{TC}}=0.078 \mathrm{G}$ psi and at its hot face is given by $\sigma_{T H}=0.022 \mathrm{G} \mathrm{psi}$; and that for a lateral g-load $\mathrm{G}$, the maximum bending stress $\sigma_{B}$ at the assembly's cold end is $\sigma_{B}=0.343 \mathrm{G} \mathrm{psl}$. Thus, the cold-end bending stress is dominant.

\section{CONCLUSION}

The peak load of $-500 \mathrm{~g}$ obtained for all three cases corresponds to a maximum bending stress of 172 psi at the cold ends of the thermoelectric legs perpendicular to that load. Previous measurements indicate that a stress of 172 psi could be easily tolerated by the SIGe legs and the glass bonds. Therefore, the new analyses indicate that the Figure-3 RTG design and the Figure-11 lander design would enable impact survival without retrorockets. This could substantially reduce the system's cost and complexity.

\section{Acknowledgment}

The above work was supported by the Department of Energy's Office of Special Appllcations (R. Lange, Director, and E. Mastal, Deputy Director). 


\section{References}

[1] JPL Exploration Precursors Task Team (1989) "Misalon Conoept and Development for Mars Global Network Mission," Jet Propulsion Laboratory. Pasadena, Calllornia, December 1989.

[2] Ames Research Center (1991) "Mars Environmental Survey (MESUR) Sclence Objective and Mission Description, - National Aeronautics and Space Adminlstration, Ames Research Center, Calltornia, July 1991.

[3] Schock, A. (1991) "Design of Small Impact Resistant RTGs for Global Network of Unmanned Mars Landers," 42nd Congress of the International Astronautlcal Federation held in Montreal, Canada, October 1991.

(4) Schock, A. (1980) "Design, Evolution and Verification of the General Purpose Heat Source, $"$ "809203 Proc. of the 15th Intersociety Energy Convorsion Enginearing Conference, hoid in seattle, Washington, 1980.

[5] Schock, A. (1979) "Design, Analysis and Optlmization of FTC for Solar Polar Mission," Proc. of the 14th Intersoclety Energy Converslon EngIneering Conlerence, held in Boston, Massachuselts, August 1979.
[6] Schock, A. (1981) "Modular Isotopic Thermoelectrio Generator," "819174 Proc. of the 16th intersociety Energy Conversion Engineering Conference, held in Atlanta, Georgia, August 1981.

[7] Schock, A. (1983) "MITG Test Assembly Deslgn and Fabrication," "\$839173 Proc. of the 18th Intersociety Energy Conversion Englneering Conference, held in Ortando, Fiorida, August 1983.

[8] Pohl, W., M.J.v.d. Hoek, J.P. Buls, C.J.L. Florle, S.L. Hancock, P.H.L. Goenenboom, D.J.E. Hesselink, H. Lensellink, and P.J.J. Schatlers (1984) The PISCES Software for DEFENSE. The Netherlands. PISCES Intemational, B.V., 1984.

[9] Dunbar, George, Physics International, Personal Communication, September 1986.

[10] Cowler, M., Birnbaum, N., (1990) AUTODYNE-3D. Century Dynamics, Oakland, Callfomia, 1990. 